\title{
A Qualitative Exploration of Social Media Consumption and Use Among Everyday Women Who Participate in CrossFit
}

Original Research

\author{
Christina Gipson ${ }^{1}$, Nancy L. Malcom ${ }^{1}$, Caitlyn Hauff ${ }^{2}$, Hannah Bennett $^{3}$, Arshpreet Kaur Mallhi ${ }^{1}$ \\ ${ }^{1}$ Georgia Southern University, Statesboro, GA/USA \\ ${ }^{2}$ University of South Alabama, Mobile, AL/USA \\ ${ }^{3}$ Augusta University, Augusta, GA/USA
}

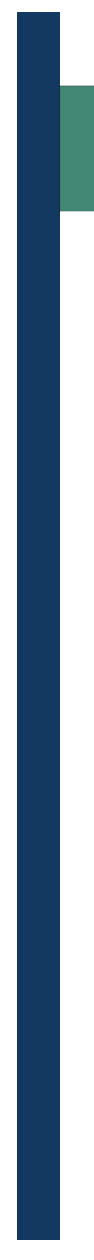

Open Access

Published: January 10, 2022

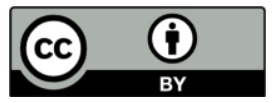

Copyright, 2022 by the authors. Published by Research Directs and the work is licensed under the Creative Commons Attribution $\quad 4.0$ International License. To view a copy of this license, visit

http://creativecommons.or g/licenses/by/4.0/

Research Directs in Health Sciences: 2022, Volume 2 (Issue 1): 2

ISSN: 2768-492X

\begin{abstract}
Introduction: Social media allows a user to be a content creator and consumer. This paper focuses on the social media engagement of everyday women who participate in CrossFit, exploring differences in how they consume and use social media content. CrossFit women are celebrated for their strength, power, and fitness in the social media community, which is not consistent for all women.

Methods: This study used semi-structured focus groups with 47 participants between the ages of 18-54 who were everyday women who participate in CrossFit. The participants self-identified their level of CrossFit as recreational, semicompetitive, competitive, or high-level competitors.

Results: Findings reveal two major themes: consuming corporate messaging and using social media for their own benefit, included the subthemes of social support and shifting perceptions. The findings, including supportive quotations from the participants, reveal that these women are critical consumers of social media who express disapproval of traditional media portrayals of women's bodies.

Conclusions: Women's experiences with CrossFit seem to offer some protection from the negative outcomes associated with consumption of traditional media messaging about women's bodies.
\end{abstract}

Key Words: Social media as a protection; consumption of media; experiences of women.

Corresponding author: Christina Gipson, cgipson@georgiasouthern.edu

\section{Introduction}

The media landscape has changed drastically over the past two decades. Traditionally, businesses and media companies were the producers of content seen in print media, like magazines and newspapers. However, the introduction of social media has broadened who produces content, while also providing space for consumers to challenge ideas and worldviews once established and maintained through traditional media. CrossFit adapted their business model to embrace the advances in media technology through the use of an open-source fitness model where affiliate owners and CrossFit athletes used virtual forums to co-produce and consume information. ${ }^{1}$

There is a substantial body of literature examining the effects of print and social media engagement on women's health, self-esteem, and body image. Dominant messages conveyed by traditional media have historically promoted traditional 
femininity and a thin body, ${ }^{2,3}$ which are linked to negative health outcomes for women who consume this media. for the consumer. Recently, there has been a move to include a wider variety of body types in media images. ${ }^{4}$ A 2011 American Medical Association (AMA) report ${ }^{5}$ highlighted how fashion industry leaders responded to health policy recommendations by reducing the number of images featuring underweight models; the AMA report advocated for more representative images that include "normal" and "real" models. These changes reveal how marketers use implicit and explicit cues and messages to promote the acceptance of larger body types, yet health scholars question whether changes in media portrayals are sufficient for promoting healthier lifestyles. ${ }^{4}$ While it has been established that, social media generally has a negative impact on a female's body image, it is unclear how marketing to a wider audience of varying body shapes and sizes might encourage support for acceptance of differing body sizes. Women's bodies are the focus of some spaces, particularly athletics, and therefore, it is important to identify how women in these spaces might engage with social media related to body image.

Athletes are often considered to represent the epitome of good health, yet even athletes are not immune from body image issues. In fact, women involved in sports and fitness may be at higher risk because they are exposed to, and impacted by, both sociocultural and sport-specific expectations related to body shape, size, weight, appearance, and eating. ${ }^{6,7}$ Factors such as level of participation, age, and degree of travel shape female athletes' risk level when it comes to body image issues. ${ }^{8}$ Studies reveal that sports which emphasize bodyweight control (e.g., running, synchronized swimming, rowing) are linked to higher levels of body dissatisfaction. ${ }^{9}$ Also at higher risk of body dissatisfaction are athletes who participate in aesthetic sports such as gymnastics and figure skating. ${ }^{10-12}$ The appearance ideals promoted in these sports compound the messages about feminine beauty that are found in media, leading to similar negative attitudes, emotions, and beliefs about beauty and the body. ${ }^{13}$ Even though athletes construct their bodies to be functional for their sport, ${ }^{7}$ research has shown that in some cases, an athlete's emphasis on appearance can surpass the focus on athletic accomplishments. ${ }^{14}$ One growing sports arena worthy of exploring in relation to body image is CrossFit. CrossFit is unique in that it combines elements of both traditional aesthetic sports (e.g., gymnastics) and nonaesthetic sports (e.g., weightlifting). While some studies have explored body image related to female CrossFit athletes, ${ }^{15}$ it is relatively unknown how social expectations via social media inform, defy, or support body image ideals in these women and how that relates to perceptions of themselves, the sport, and their performance.

CrossFit, founded in 2001, involves a training methodology combining metabolic conditioning, gymnastics, Olympic lifting, and functional movements to create challenging, high-intensity workouts. ${ }^{16-19}$ All workouts are thought to be accommodating and welcoming to all people regardless of experience, body type and ability level..20 For many participants, the CrossFit community extends beyond the gym walls. CrossFit's open source model capitalizes on technology, where participants have access to workouts, scores, instructional videos and exercise demonstrations. CrossFit's early online presence helped to spread the CrossFit philosophy, contributed to the rapid expansion of the CrossFit brand, and laid the groundwork for a burgeoning online CrossFit community. ${ }^{1}$ CrossFit undoubtedly benefited from its early adoption of social media technology, and serves as one example for how this technology changed the social landscape across the globe. One of the benefits of the shift away from traditional media towards social media was that consumers now have the ability to interact with each other, which encourages them to become media users (rather than just consumers) and opens up the possibility that they will become content producers. This social media shift promotes greater social cohesion and feelings of connection among the consumer/users. ${ }^{21,22}$ Not only do the CrossFit social media platforms provide a space for people with expertise to share their knowledge, but they also nurture the development of close and mutually-supportive relationships. Studies have demonstrated that CrossFit encourages women's physical strength and muscularity which positively impacts body image. ${ }^{23-25}$ However, some scholars pointed out that images in the CrossFit Journal reinforces stereotypical notions of femininity. ${ }^{26}$

CrossFit's online presence welcomes all skill levels, levels of experience, and body sizes. This creates a powerful position for the CrossFit participant, as they have the ability to produce content that not only creates an identity for themselves, but allows the participant to put themselves on display, aesthetically and performance-wise, for the consumption of others. Consequently, social media creates a space ripe for social comparison, which research indicates has been problematic for female body image. ${ }^{27-29}$ There is minimal research that highlights the experiences of women who CrossFit and their engagement with CrossFit-related social media. Although the perception is that a strong CrossFit community celebrates and supports female CrossFit athletes, it is unclear if that support extends beyond physical accomplishments into the realm of body transformation.

The culture of CrossFit tends to counter traditional messaging by providing women with alternate messages about strong bodies. While this alternative messaging is positive for body acceptance, engagement with social media might 
influence the tone of these messages, particularly as users consume and produce their own media content. Thus, the purpose of this study is to explore how CrossFit women engage with both traditional print media and social media content. The study examines (1) how women who participate in CrossFit engage with media platforms, and (2) whether social media provides these women with new opportunities to shape a positive self-image.

\section{Scientific Methods}

This study used semi-structured focus group interviews to explore the media consumption and use of everyday women who participate in CrossFit. A narrative approach was employed which allows participants to share from their own viewpoints, enabling them to "express emotions, thoughts, and interpretations". ${ }^{30}$ When exploring a participant's lived experience through a narrative approach, researchers often tie the story together with a common thread that provides meaning and foundation. ${ }^{31}$ For this study, the common thread was how the participants engaged with traditional print media and social media. Through focus groups, participants could enhance disclosure, create comfort in sharing similar experiences, and provide more elaborate and detailed experiences in reaction and response to other focus group members. ${ }^{32}$

\section{Recruitment and Ethical Considerations}

Participants were recruited from CrossFit gyms in three different locations, all in rural southeastern United States. Recruitment was purposeful and convenient due to the proximity of gyms to members of the research team. Sign-up sheets were placed within local gyms and interested members who fit the inclusion criteria signed up to receive information and to be scheduled for focus group interviews.

Focus group sizes ranged from three to six participants. In most cases, the women who participated in each focus group knew each other and were members of the same gym. This familiarity helped to make the participants feel comfortable in sharing their stories, allowing for rich data to be gathered. Focus groups took place in quiet, private locations convenient to each group. At the start of each focus group, interview procedures were explained and informed consent was obtained. After consent was obtained, each participant completed a demographic sheet that included questions reflective of their identity and experience within CrossFit, such as ethnicity, education, length of time participating in CrossFit, and skill level within CrossFit. Pseudonyms were used for each participant and omitted any uniquely identifying information. All components of this research, including interview procedures, assurance of confidentiality, and methods for obtaining informed consent were approved by the Institutional Review Board. Furthermore, interviews for this research were collected prior to the pandemic and all necessary safety measures were ensured for participant and researcher.

Participants

To be eligible for this study, the participant needed to be a self-identifying woman who was involved in CrossFit. A total of 47 female participants took part in 11 focus groups. The participants ranged in age from 18 to 54 years old, with more than half of the participants $(N=26)$ being 35 years of age or older. While most of the participants identified as White $(N=40)$, one participant identified as American Indian, two identified as Black, and four identified as multiracial. The participants reported varied educational levels, ranging from high school or GED completion to advanced graduate and professional degrees. Each participant provided a self-assessment of her skill level, and nearly half $(N=22)$ described themselves as recreational CrossFit athletes; 16 of the women described themselves as semicompetitive, while six identified as competitive, and three identified as high-level competitors. Twenty-one participants reported that they had been involved in CrossFit for more than two years, while 13 had been involved between one and two years, 11 had been involved between six months and one year, and two women had been involved in CrossFit for less than six months. See Table 1 for a list of participants and their demographic information.

\section{Data Collection}

Focus group interviews lasted between 45 minutes and 2 hours. All focus group interviews were audio-recorded and then transcribed verbatim. The interviewer guided discussion by using a basic set of predetermined questions, but participants were encouraged to share stories that related to the questions and the interviewer would follow up with question probes. Many times, arguably due to the comfort level felt by the focus group participants, personal stories were shared in parallel with someone else's similar experience. Focus group questions focused on media, body image, and impact of CrossFit. Saturation was met as the researchers recognized a redundancy and repetitive nature regarding participants' experiences and stories across the eleven different focus groups. 
Table 1. Focus Group Participants

\begin{tabular}{|c|c|c|c|c|}
\hline Pseudonym & $\begin{array}{l}\text { Focus } \\
\text { Group }\end{array}$ & Age & Race/Ethnicity & CF Level \\
\hline Christine & 1 & $18-24$ & White & Competitive \\
\hline Sage & 1 & $18-24$ & White & Competitive \\
\hline Harper & 1 & $25-34$ & White & Semi-competitive \\
\hline Ryan & 1 & $25-34$ & White & Semi-competitive \\
\hline Melinda & 2 & $45-54$ & White & Recreational \\
\hline Leticia & 2 & $25-34$ & White & Recreational \\
\hline Erica & 2 & $35-44$ & White & Recreational \\
\hline Katie & 3 & $45-54$ & White & Semi-competitive \\
\hline Ashley & 3 & $25-34$ & White & Recreational \\
\hline Sarah & 3 & $25-34$ & White & Semi-competitive \\
\hline Erin & 3 & $35-44$ & Am. Indian/Alaskan Native & Recreational \\
\hline Janelle & 4 & $25-34$ & White & Competitive \\
\hline Tracy & 4 & $35-44$ & Multiracial & Competitive \\
\hline Cathy & 4 & $25-34$ & White & High-level competitive \\
\hline Cinnamon & 5 & $25-34$ & White & Semi-competitive \\
\hline Mariel & 5 & $35-44$ & Black/Af. Am. & Recreational \\
\hline Anastasia & 5 & $25-34$ & Black/Af. Am. & Recreational \\
\hline Athena & 5 & $45-54$ & Multiracial & Semi-competitive \\
\hline Jessica & 6 & $35-44$ & White & Recreational \\
\hline Henri & 6 & $35-44$ & White & Recreational \\
\hline Emily & 6 & $18-24$ & White & Recreational \\
\hline Jada & 6 & $25-34$ & White & Recreational \\
\hline Bonny & 7 & $35-44$ & White & Recreational \\
\hline Tonya & 7 & $35-44$ & White & Recreational \\
\hline Fern & 7 & $35-44$ & White & Recreational \\
\hline Farah & 7 & $35-44$ & White & Semi-competitive \\
\hline Suzanne & 7 & $35-44$ & White & Recreational \\
\hline Sandra & 7 & $45-54$ & White & Recreational \\
\hline Samantha & 8 & $35-44$ & White & Semi-competitive \\
\hline Alex & 8 & $35-44$ & White & Semi-competitive \\
\hline Jackie & 8 & $35-44$ & White & Recreational \\
\hline Hope & 8 & $35-44$ & White & Recreational \\
\hline Laura & 8 & $35-44$ & White & Recreational \\
\hline Marianne & 8 & $35-44$ & White & Recreational \\
\hline Mariah & 8 & $35-44$ & Multiracial & Recreational \\
\hline Holli & 9 & $25-34$ & White & Recreational \\
\hline Veronica & 9 & $18-24$ & White & Semi-competitive \\
\hline Camille & 9 & $18-24$ & Multiracial & High-level competitive \\
\hline Miranda & 9 & $25-34$ & White & Competitive \\
\hline Maggie & 9 & $35-44$ & White & Semi-competitive \\
\hline Star & 10 & $35-44$ & White & Semi-competitive \\
\hline Rue & 10 & $25-34$ & White & Semi-competitive \\
\hline Mary & 10 & $18-24$ & White & Semi-competitive \\
\hline Arden & 10 & $35-44$ & White & Semi-competitive \\
\hline Red & 11 & $35-44$ & White & Semi-competitive \\
\hline Rose & 11 & $18-24$ & White & Competitive \\
\hline Cara & 11 & $25-34$ & White & High-level competitive \\
\hline
\end{tabular}

\section{Data Analysis}

Following the completion of the focus groups, all recordings were transcribed and the research team employed multiple levels of analysis in a recursive process consistent with qualitative research. ${ }^{33}$ The first round of the qualitative analysis 
consisted of researchers coding interviews independently of one another. To do this, individuals read through the transcripts in order to familiarize themselves with the data and then independently identified emerging themes for a thematic analysis. Based on availability of software, individuals on the research team loaded the data into either MAXQDA or NVivo and proceeded to code the data. The second round consisted of the research group meeting to discuss initial codes and to reach consensus on final codes. Two important themes that emerged from the initial reading of the transcripts revolved around body image perceptions and media engagement. Table 2 provides a sample of some of the codes that were created based on these themes. Data analysis then led the researchers to recognize the importance of distinguishing between media consumption, use, and production. This key distinction led to the final findings, which highlight the ways that the women become critical consumers of traditional media while also actively using social media to increase social support and shift their perceptions of women's bodies.

Table 2. Sample Codes

\begin{tabular}{|l|l|}
\hline Code & Application of Code \\
\hline beauty ideal & Applied to any mention of traditional standards of female beauty (thin, beautiful) \\
\hline body acceptance & $\begin{array}{l}\text { Applied when participants discuss accepting \& appreciating their own body } \\
\text { (shape \& size) }\end{array}$ \\
\hline body dissatisfaction & Applied when participants discuss being dissatisfied with any part of their body \\
\hline print media & $\begin{array}{l}\text { Applied to any discussion of traditional media (fashion magazines, billboard } \\
\text { advertisements, etc.) }\end{array}$ \\
\hline CF media & $\begin{array}{l}\text { Applied to any media messaging by CrossFit Headquarters (CF websites, CF } \\
\text { Journal, etc.) }\end{array}$ \\
\hline social media & $\begin{array}{l}\text { Applied to any mention of engaging with social media (Instagram, Facebook, } \\
\text { Twitter, etc.) }\end{array}$ \\
\hline social media relationships & $\begin{array}{l}\text { Applied to any mention of interacting with others through social media accounts } \\
\text { (sharing, following, commenting on social media feeds) }\end{array}$ \\
\hline
\end{tabular}

\section{Results}

Results revealed two major themes with subsequent subthemes. The first theme, consuming corporate messaging, included the subthemes of mixed messages and social comparison. The second theme, using media for their own benefit, included the subthemes of social support and shifting perceptions. The findings, including supportive quotations from the participants, are detailed in this section. Pseudonyms are used throughout to ensure confidentiality.

\section{Consuming Corporate Messaging}

As a corporation, CrossFit actively manages its brand through media publications, such as the CrossFit Journal and articles and blogs on the CrossFit website. In addition, CrossFit sponsors create media content that is intended for CrossFit participants to consume. Focus group discussions revealed that the women in this study are active consumers of CrossFit-related media and that they are highly aware of the ways that this media portrays women's bodies. Even as corporate entities create messaging about women's bodies, most of the participants expressed disapproval of these portrayals and are critical of the ways that the fashion and fitness industries seem to have merged, such that this media promotes mixed messages about the "ideal woman." Throughout the interviews, the participants referenced advertisements from the CrossFit industry leaders. The participants noted that most of the advertisements produced by these corporations conform to wider societal norms, framing the "ideal CrossFit woman" as someone who is both toned and skinny. Maggie noted that advertisements encouraged CrossFit women to "look strong but still be skinny," and Anastasia highlighted how both advertisements feature videos of elite athletes on social media who "balance being sweaty and beautiful." Throughout the interviews, the participants went back and forth addressing in their discussions the benefits of using social media, but also their recognition of the problematic aspects that persist in so many corporate 
ads. Findings revealed two subthemes related to the participants' consumption and use of corporate messaging: mixed messages and social comparison.

Mixed Messages

The concept that women were supposed to look strong but be skinny or that they should balance being sweaty while also beautiful were described by the interview participants as internal contradictions. When participants consumed this messaging, they viewed it critically, questioning its relevance for their own experiences in CrossFit. Most of the participants stated that the advertisers' body ideals were unachievable and that they do not represent the typical woman who participates in CrossFit. Jada reflected on this messaging by saying, "you have to be very thin, blonde hair, blue eyed, long gorgeous locks ... [and that's] not me, not who I am." Erin underscored this feeling, stating that she cannot relate to the unrealistic media portrayals. She further explained that she subscribes to a CrossFit magazine with numerous advertisements and that "even the girls in there, it's not like the girls who do CrossFit at the Games ... it's just like some fitness model and they're wearing the advertiser's clothing."

Beyond questioning whether the women in advertisements are actual athletes, some of the participants stated that they have lost faith in the industry, mainly due to the touch-up techniques used in their ads. Several focus groups discussed the use of airbrushing and Photoshop techniques used to alter images, which the participants complained makes the images unrealistic and even less representative. Maggie recounted a well-known and controversial moment in 2014 when the cover of a magazine featured an altered photo of an athlete, who had been crowned "Fittest Woman on Earth." As Maggie explained, the altered image "made her thighs and ass look smaller. . The CrossFit community was super pissed. That's not us!" Several of the participants indicated that their participation in CrossFit is what led them to start questioning media images. Many of the participants acknowledged that when they first joined CrossFit, they did so to lose weight, but as they continued with CrossFit their focus shifted. Erica explains, "it wasn't until I started CrossFit that I realized what a bad message most of them [traditional magazines and advertising] send. I wanted to be thin, but I really didn't pay much attention to it until CrossFit." Erin concurs, stating, "I've stopped subscribing to [magazines]. . . because it's like, what's the point? Why is make-up in a fitness magazine?" Erin is similarly critical of CrossFit-specific media, stating:

"How can you ... talk about being fit and certain sizes or whatever, but have an article about, I don't know, a fit, curvy girl, her story, and then you turn around and the next page is a skinny model in a $\$ 300$ pair of whatever and sports bra - this is ridiculous, this is not my person!"

As consumers of CrossFit-related media, the participants noted the mixed messaging when the media included stories about strong women who sweat as they build muscle, but also included advertisements featuring skinny women who smiled at the camera. Their experiences in the CrossFit gym does not match what they see portrayed in much of the CrossFit-related media.

\section{Social Comparison}

As the participants discussed their consumption and use of media, it became clear that media content created space for social comparison. During interviews, the participants made a distinction between the slick advertisements and promotional materials created by CrossFit gyms, such as CrossFit, Inc. and their sponsors, and the independently created social media accounts belonging to individual athletes. The CrossFit industry used these promotional materials to craft an image that was appealing to the consumer. Ironically, this emphasis on "image" resulted in the industry's creation of media which the participants deemed unrealistic and non-relatable, while also feeling encouraged to compare their appearance and abilities against those being placed on display.

Findings suggest that a key distinction between traditional media (created by the industry with the consumer in mind) and social media (generated by the user, often to promote interaction) is whether the media images emphasize an end product or a process. Industry-created advertisements and promotional materials focus on the "end product" - an attractive, well-toned but not-too-muscular woman who appeals to a broad audience. The process of achieving that perfect image - a process which includes hours of work to achieve a toned body, but also requires airbrushing out the imperfections - is hidden from the consumer. Time and again, the participants stated that what they liked about following other athletes on social media is being exposed to the hard work and effort (i.e., the process) that those athletes put in as they work toward their goals. By following an athlete's social media feed, regardless of whether that athlete is a novice or an elite competitor, it is possible to track the athlete's progress from day to day and week to week as she sets new, self-generated personal records. Social media accounts provided consumers with a behind the scenes look, allowing consumers to watch videos that capture hard workouts and see photos of dinner plates featuring body- 
fueling foods. Ashley shared that she came to this realization after connecting with her coaches on Facebook. She explained how her coaches had posted "before and after pictures of when they weren't fit versus where they are now." Ashley emphasized:

“That's very inspiring, because I think it's very relatable. You don't just look at them and BAM they just got like that when they walked in the door. But social media is helpful with that - for people that will share their journey of where they were versus where they are now and how much time and dedication that took."

Even though the most popular social media accounts are generated by elite athletes whose accomplishments might seem far removed from the participants, because the social media accounts of elite athletes tend to focus on fitness as a work in progress rather than an outcome, their stories were relatable to the participants in this study. When talking about her experience following elite athletes on social media, Henri explained: "you know they didn't get there by starving themselves, right. And that is something I want to work on." Anastasia pointed out that the main reason she follows CrossFit athletes on social media is because she is impressed by "the hard work that they put in." Courtney stated that what matters most is "what you can do physically, not what you physically look like." Jackie went even further, stating it is the ethic of hard work that binds all CrossFit athletes:

"What I see on social media is that most women of CrossFit - at the elite level or any level - they're not in it for perfection of body image, they're in it for what they're capable of. They're not doing it so they look perfect or have the perfect body image."

In addition to this shared work ethic, the diversity of elite athletes who post on social media is also appealing. Sarah mentioned, "They all look different" and she links this diversity of physical appearance to a focus on process over product. As Sarah explained, "there is not a perfect body ... [elite athletes] are in it for what they're capable of. They are not doing it so they look perfect or have a perfect body or that they can wear anything." Similarly, Tonya observed "there's not just one triangle that fits in the little triangle space." These comments suggest that unlike traditional media, which produces a narrow image of the "ideal CrossFit woman," social media is more representative and as a result, more relatable for everyday women, even when the social media accounts are created by elite athletes.

However, the participants revealed that they do make social comparisons and that there is the potential for these comparisons to have negative effects, though positive benefits of social comparison seemed to outweigh the negative. A few participants did talk about ways that media portrayals of the "ideal woman" left them feeling inadequate. For example, Laura shared the following:

"I know that I'm strong because I can do all these things, but I think still in the back of my mind, and when I see magazines or I see TV or even CrossFit ads, I still [wonder] . . . would I trade the strength and the talent to never have to worry ... to just look like that?"

While Laura's comment illustrates that comparisons between oneself and "ideal" others can lead to negative feelings, far more of the participants talked about the ways that media portrayals were unrealistic and unrepresentative. This suggests that when they compare themselves to traditional media images, they conclude that the media images, rather than their own bodies, are problematic. Erin canceled several magazine subscriptions once she realized that their portrayals of women were unrealistic. Similarly, Henri shared, "I noticed every time I read magazines, I felt damned, so I just stopped." Henri went on to explain that she is now selective in choosing the media which she consumes, and that she will "watch the CrossFit Games and the Olympics, but I feel like those are good ads." Interestingly, as the participants discussed the ways that they make conscious decisions to avoid problematic messaging and to selectively consume positive portrayals of women, they acknowledged that their participation in CrossFit might have given them the tools to make these decisions. When talking about traditional media portrayals of the "ideal woman," Maggie explained that "these are not the messages being supported by everyday women interested and involved in CrossFit." Rather, as Maggie and others in the focus groups conceded, women who are not involved in CrossFit might be more susceptible to the negative body images that are so prevalent in the media. Thus, their experience in CrossFit has prompted them to be active users of media content, carefully curating the media that they chose to consume.

When discussion shifted towards the participants' consumption of social media, it was apparent that many of them do follow elite female CrossFit athletes on social media platforms. However, instead of comparing their bodies to those of elite athletes and concluding that they do not measure up, comments from participants in this study demonstrated that they find connections based on shared values and goals. Previous discussions emphasized the ways that the participants appreciated the diversity of body types that are represented through social media accounts, and that they enjoyed seeing photos and videos that highlight the hard work that elite athletes put into improving their physical skills. 
Rose described CrossFit women, saying "They aren't skinny little girls you see in magazines. And they are real. They are all sorts of sizes, you see them on Instagram." Leticia noted that she used social media to follow "super muscular elitist CrossFit women that I want to be like" but she also admitted that she "can't compare much." Brittany shared that watching elite CrossFit athletes, "made me want that kind of body even more." She elaborated, "I'm following all of them on Instagram, and I'm seeing that I'd love to look like that." Though this could be interpreted as a negative comparison whereby Brittany felt like she did not measure up, Brittany's background led to a different understanding. Brittany explained that as a child she was always larger and more muscular, and because of that she never felt as though she fit in. But CrossFit has provided a space - both in real life and through social media - where she sees bodies that are more in line with her own. Sage also highlighted the positive aspects of seeing muscular women on social media, explaining, "At one point you feel like you may have been an outsider ... but now because it's so popular, there's more people out there doing CrossFit and more people doing bodybuilding and more women doing both. It's now acceptable!"

Using Media for Their Own Benefit

Interview discussions revealed that the participants in this study had a high level of engagement with social media, not simply as consumers, but also as users and producers. In all the focus groups, the major component discussed was creating a setting or network of people on social media. Mary explained, "you choose who to surround yourself with." The focus group participants were able to identify hashtags that they use to network with people who share similar interests, and they discussed specific social networks and online groups that they belong to, such as Black Girls CrossFit, CrossFit Women, Women Rx, and Girls Who Lift. Emily explained, "you pick and choose what you want to follow." In Emily's case, she follows a group called "CrossFit Girls Powerlift" on both Instagram and Facebook as the slogan drew her in: "You are not strong for a woman, you are just strong." Many participants stated that their online interactions revolved around CrossFit, with Cara stating that "everyone that I follow or are friends with, they all CrossFit," and Red commenting, "now that I'm in CrossFit, I'm more geared toward social media to go look at CrossFit geared stuff." Katie explained, "I need to surround myself with people...that have alike thoughts and views and who are striving for the same thing." The participants in this study were high engagers with social media content. From their conversations of their social media use, two sub-themes emerged: social support and shifting perceptions.

Social Support

The participants described actively creating networks with likeminded people. Through these networks, they developed a sense of belonging in an online space. CrossFit is known for creating strong community bonds and many focus group participants described their local gym as a tight-knit community. Yet Janelle explained how social media "makes the community a lot larger." Viewing the online community as an extension of the gym, several participants pointed to social media outlets as important sites for learning tips that help to improve their technique. For instance, Cara and Brittany explained that they follow bodybuilders on social media to get ideas about movements that strengthen certain muscle groups, while Harper talked about following a hashtag Hookgrip on social media for technique tips in Olympic weightlifting. Brittany explained that social media also allows users to produce content about their own progress, which in turn opens the door for them to receive feedback from others. Veronica referenced this when she shared:

"I like the CrossFit community because I feel like it doesn't matter what video I post, somebody always has something to say positive. Whether it's when I walk in the gym and they're like, 'Hey, I saw that thing you did,' and I'm like, 'Hey thanks, that was PR' and they're like, 'What? That's crazy!' ...even if it's somebody you know or you don't know that follows you, that just likes my video - it makes you feel good."

While the participants in this study gained inspiration from following elite CrossFit athletes on social media platforms, they found support and camaraderie by following each other online. Nearly every participant was able to provide examples of offering and receiving encouragement and positive feedback from her online networks. Miranda's comments highlighted the importance of community and having the sense of belonging. When reflecting on her use of social media, Miranda explained:

"From a confidence standpoint, when I go to post stuff, it's a confidence booster ... I use it as an outlet and I use it as a way to prove to myself that I'm worthy, that I'm supposed to be here, I'm worth something. Who knows if this is what I'm meant to do, but I'm having fun doing it, and it's keeping me in a positive frame of mind."

Shifting Perceptions

The participants in the study discussed the ways that participating in CrossFit and engaging with people and companies through social media have assisted them in changing their mindset. As CrossFit promotes being inclusive, Tonya 
recalled conversations around a top athlete, who was crowned "Fittest Woman on Earth." When she was competing, the athlete had a shaved head, placing her appearance well outside the norms of traditional feminine beauty. Tonya noted how social media content celebrated the athlete for her abilities and skills, which were more important to the content creators than her physical appearance. This led Tonya to comment, "there's just not one triangle that fits in the little triangle space." CrossFit's traditional media sources did not pay as much attention to the athlete despite her athletic prominence, which caused Tonya to feel even more affinity for the athlete and to develop a greater appreciation for social media as a space where both recreational athletes and elite athletes can share insecurities and challenge social norms. Such insecurities were seen with other elite athletes. Another top athlete shared on her personal social media page that "my body does not look like all the other female athletes at the games with crazy ripped abs and zero body fat on their stomachs. I wish I could look like that, but I've come to the realization that this is my body." After reading this post to the focus group, Anastasia referenced elite athletes, stating that elite athletes "think the same way we do and they are the same as we are." Conversation about the same Instagram post came up in another focus group, with Courtney highlighting that elite athletes' confessions about their own body insecurities helps to provide greater acceptance for women of all shapes and sizes.

Conversations throughout the focus groups highlighted that their involvement with CrossFit and consuming elite athletes' social media pages has helped them to better understand the fitness philosophy, focusing more on functional fitness rather than body image. Although weight-loss or physical appearance might have been the reason many of the participants started CrossFit, once they became immersed in the culture, they began to care more about what their bodies could do. Jada spoke about this new mindset, sharing that rather than losing weight, the goal is "to get stronger!" Sara stated that the philosophy "talks a lot about functionality and functional movements that you're going to apply to your life." Janelle explained that seeing other people's successes on social media helped her set new physical goals, saying to herself, "man, how is she able to do that right, why can't I do that?" Similarly, Hope described how following elite CrossFit women on social media influenced her to change her perceptions, stating that when she began CrossFit, she "just wanted to be a little bit toned," but then she started following elite athletes, and "when you see those ladies ... now when I see them I want to be able to clearly see defined muscles [in my own body]." Hope further explains, "That's because of the images I see on social media, Facebook." Rose described the images of CrossFit women representing people that are "STRONG!" Maggie furthered the conversation by explaining that CrossFit athletes admire and support other CrossFit athletes' transformational and progress pictures on social media, even when people outside of CrossFit make negative comments. She said "everyone in CrossFit is like 'that is amazing. I know what you can do with that body." With the increase of social media use, there has been an increase in the number of posts by elite and non-elite female athletes, and therefore, consumers are being exposed to more toned, muscular women. In fact, Sage stated:

"It's reinforced my views and made them more acceptable. At one point you feel like you may have been an outsider and then connecting with people who also idolize this body type, it makes you feel better about it and more likely to set that as a goal. Ten years ago you saw Dana Linn Bailey and you're like hey I want to be that muscular and that ripped and everyone would think you're a weirdo, but now because it's so popular, on social media, there's more people out there doing CrossFit and more people doing bodybuilding and more women doing both. It is now acceptable!"

Ultimately, the participants in this study who viewed social media content produced by other CrossFit athletes reported a growing appreciation for the variety of body shapes and sizes. They also indicated having greater recognition of the multitude of ways in which a body can be strong and powerful

\section{Discussion}

This investigation revealed that the participants are critical consumers of media. They are aware of the many media portrayals of women's bodies that are ubiquitous in magazines, advertisements, videos, and social media outlets, but they do not passively consume these messages. Rather, these participants exhibit recognition of the problematic nature of media content. Through their careful evaluations, the participants concluded that much of the content they consume, especially images found in advertisements and promotional materials created by CrossFit Headquarters and its corporate sponsors, are unrealistic and unrepresentative of actual women who engage in CrossFit. Because of this, the participants in the study exerted their agency by selectively consuming media and mindfully shaping social media networks in order to expose themselves to more realistic and representative images of women's bodies, showing preference for messages that emphasize the process of the physical and mental transformation experienced through engagement in CrossFit, rather than solely focusing on the body as an objective product. 
Body Ideals and Social Comparisons

Participants in this study admitted to using media outlets as a means to socially compare themselves to other CrossFit women participants, not only in terms of skill-related progress, but also in relation to body transformation. Even as much of the prior research focuses on negative outcomes of social comparisons the participants in this study shared experiences of how their personal engagement with CrossFit and related media content created a nuanced protection against these negative outcomes. Specifically, the focus groups discussions revealed that participants believe that the activity of CrossFit is useful in helping them to reframe what the "ideal woman" looks like, and this reframed perspective translates to how they consume CrossFit-related media content. CrossFit Headquarters does have a tendency to push an "ideal" image of a CrossFit woman that aligns heavily with traditional societal norms for beauty, and thus, engagement in any sort of social comparison with these images could potentially result in numerous negative psychosocial health outcomes. However, the participants reported using social media as a means to gain inspiration, in addition to accepting that bodies are different and capable of excelling in the CrossFit world. Although the participants in this study were well aware that the fitness industry advertises a particular image of the "ideal CrossFit woman," their experiences in CrossFit helped them recognize the unrealistic nature of this message, and further rejected this image as ideal. It is not entirely clear as to why participation in CrossFit might serve as a protective factor against negative psychosocial outcomes related to upward social comparison, but prior research suggests that women who embrace feminist or postfeminist beliefs may be protected from body image disturbance. ${ }^{34,35}$ Podmore and Ogle ${ }^{36}$ suggest that some CrossFit boxes tend to support a muscular female body, and encourage an ideal that is "strong-appearing" (pg. 11). This body type breaks away from traditional societal standards for female beauty, ${ }^{26}$ and could potentially be a driving force behind why CrossFit has protective properties. Podmore and Ogle ${ }^{36}$ also found that CrossFit communities created space for a variety of body ideal aspirations, with participants expressing goals of obtaining an "athletic", "health-focused", or "traditional" ideals (pg. 13). Participants in the aforementioned study ${ }^{36}$ even stated that their experience in CrossFit has led them to strive for body acceptance, promoting the need to accept themselves where they are at and focus on their body's capabilities versus meeting a defined norm. The participants shared similar sentiments to this, leading to the conclusion that CrossFit may provide some protection against negative body image, but much of this protection might be dependent on the culture of the box, and the social media communities that the participants created and engage in.

Social Media Engagement and Community Support

This study demonstrates that women do not simply consume media, but that they actively use social media to build supportive communities. Though the CrossFit gym often serves as a supportive community, social media platforms expand this community, offering the potential to interact with other CrossFit athletes from around the world, bringing together like-minded women who can gain inspiration and motivation from each other. Participants describe this digital community as a space where athletes celebrate each other, regardless of skill level and body type, and where positivity reigns. The positive community that CrossFit engenders both online and offline has instituted an atmosphere where comparison is utilized to encourage others to push their performance standards, provide inspiration, and allow women to focus on strength and functionality. ${ }^{36}$ The participants note that social media allows them to interact with other CrossFit athletes whom they admire and respect, and that when they see these women succeed, they feel more hopeful about their own ability to engage in the same behaviors to build strength and skill. Several participants talked about using social media to seek advice and to hone their technique; other participants use social media to share pride in their accomplishments. Social media offers a space where participants openly discuss their performance in the gym, knowing that they are surrounded by a community that will be supportive and celebratory. ${ }^{37}$ This realm of positivity seems to offer additional protection for the potentially negative comparisons that have been observed elsewhere on social media. ${ }^{38,39}$ Interacting with a positive community both in-person and online seems to create an empowering experience that is beneficial to one's growth as a female CrossFit athlete.

\section{Strengths and Limitations}

This qualitative research study had several strengths. First, it represented the lived experiences of a diverse group of women who participate at varying levels of CrossFit. Second, this is one of the first studies to qualitatively explore how social media aligned with CrossFit might impact body image in women who CrossFit. Third, this study provides perspective on how women who CrossFit engage with social media and use it as a means to build community, socially compare, find inspiration, and interact with individuals they know, and even those they do not know.

There were a few limitations for this study. First, the results are unique to this subset of women and not translatable to other groups of CrossFit athletes. A second weakness to take note of is social desirability. While the benefits of focus groups were highlighted in the methods section, the research team is aware that there was an assumption that all 
participants shared their unique and personal experiences. However, some of the participants may have crafted their answer so that they were looked upon favorably by the interviewer and/or their peers. A third limitation was that the majority of the interview participants were recreational rather than competitive athletes. CrossFit competitions provide a forum where athletes interact and meet each other, increasing their social networks and introducing them to new people to follow on social media. Research involving more competitive CrossFit athletes could potentially lead to different conclusions about social media engagement. Lastly, while the researchers made a strong attempt to control for researcher bias during the data analysis process by utilizing both CrossFit and non-CrossFit researchers, qualitative research is subject to researcher interpretation, and should be mentioned as a limitation.

\section{Conclusion}

Media consumption related to CrossFit creates a variety of avenues for social comparison to occur. In trying to better understand this unique phenomenon, this study found that the participants were purposeful in consuming and interacting with CrossFit-related media content. These participants acknowledged that much like society's "ideal standard of beauty", an "ideal CrossFit body" exists and is perpetuated by some media outlets. But, their personal engagement in CrossFit has allowed them to transform the way they view their body, and the bodies of others, encouraging them to reject these ideal norms in support of body acceptance and focusing on the capabilities of one's body. These participants emphasized how CrossFit had taught them to value functional fitness, appreciating what their bodies can do, rather than being overly concerned with appearance and other people's aesthetic evaluations of their bodies. When women choose to respect and appreciate their bodies in this manner, the result is often increased body satisfaction, further protecting them from negative health outcomes associated with consuming images that might promote thin-ideal internalization. ${ }^{40}$ As suggested by many of the participants, CrossFit has provided a space for them to accept their bodies and understand that bodies come in all shapes and sizes. Though the participants in this study recognized that media created and controlled by CrossFit Headquarters often embraced society's gendered norm of the thin-ideal, the CrossFit philosophy as it is practiced in the gym endorses strength, functionality, and power. This philosophy promotes exercise as a means to enhance health and functional movement. As an aspect of body image, body functionality focuses on how the body operates in terms of its physical capacities and internal processes, emphasizing the body as a process and not as an object. ${ }^{41,42}$ Prior research has shown that women who are motivated to exercise for health-related reasons tend to have higher body satisfaction and self-esteem. ${ }^{43,44}$ Similar patterns are observed by the participants in this study. These participants expressed that social media provides a platform for CrossFit athletes to display their fitness journeys and accomplishments, highlighting their abilities and skills rather than their physical appearance. Not only do the social media platforms in which these participants engage provide them with powerful messages of body acceptance, but they also allow women to engage in positive social comparison, whether lateral or upward, as they push themselves to create better versions of themselves through engagement in CrossFit (as a sport) and with the larger community.

This research project explored the ways that everyday women who participate in CrossFit consume and use media as it relates to women's body image. The findings suggest that CrossFit women are active and critical consumers and users of media. These women seek out and help to create online communities that surround them with positivity and that emphasize process over product, thus celebrating functional fitness over appearance. In doing so, the everyday women who participate in CrossFit and the digital communities they create and participate in are transformative, helping women to change mindsets and embrace positive body images. These participants' experiences with CrossFit, both in the gym and through social media, do seem to offer some protection from the negative outcomes associated with consumption of traditional media messaging about women's bodies.

\section{References}

1. Gipson C, Bennett H, Malcom N, Trahan A. Social innovation and fitness sports: A case of the crossfit movement in north america. Social Innovation in Sport. 2021:189-205. doi:10.1007/978-3-030-63765-1_10

2. Azzarito L. Future girls, transcendent femininities and new pedagogies: Toward girls' hybrid bodies? Sport, Education and Society. 2010;15(3):261-275.

3. Krane V. We can be athletic and feminine, but do we want to? Challenging hegemonic femininity in women's sport. Quest. 2001;53(1):115-133. doi:10.1080/00336297.2001.10491733

4. Lin L, McFerran B. The (ironic) dove effect: Use of acceptance cues for larger body types increases unhealthy behaviors. Journal of Public Policy \& Marketing. 2016;35(1):76-90. doi:10.1509\%2Fjppm.14.020

5. American Medical Association. Body image and advertising to youth. AMA. 2011. http://www.amaassn.org/ama/pub/news/news/a11-new-policies.page 
6. Kristjánsdóttir H, Sigurðardóttir P, Jónsdóttir S, Porsteinsdóttir G, Saavedra J. Body image concern and eating disorder symptoms among elite icelandic athletes. International Journal of Environmental Research and Public Health. 2019;16(15):2728. doi:10.3390/ijerph16152728

7. Lunde C, Gattario KH. Performance or appearance? Young female sport participants' body negotiations. Body Image. 2017;21:81-89. doi:10.1016/j.bodyim.2017.03.001

8. Kantanista A, Glapa A, Banio A, et al. Body image of highly trained female athletes engaged in different types of sport. BioMed Research International. 2018;2018doi:10.1155/2018/6835751

9. de Oliveira GL, de Oliveira TAP, de Pinho Gonçalves PS, Valentim Silva JR, Roquetti Fernandes P, Fernandes Filho J. Body image and eating disorders in female athletes of different sports. Journal of Exercise Physiology Online. 2017;20(2)

10. De Bruin AK, Oudejans RR, Bakker FC. Dieting and body image in aesthetic sports: A comparison of dutch female gymnasts and non-aesthetic sport participants. Psychology of Sport and Exercise. 2007;8(4):507-520. doi:10.1016/j.psychsport.2006.10.002

11. Kong P, Harris LM. The sporting body: Body image and eating disorder symptomatology among female athletes from leanness focused and nonleanness focused sports. The Journal of Psychology. 2015;149(2):141-160. doi:10.1080/00223980.2013.846291

12. Robbeson JG, Kruger HS, Wright HH. Disordered eating behavior, body image, and energy status of female student dancers. International Journal of Sport Nutrition and Exercise Metabolism. 2015;25(4):344-352. doi:10.1123/ijsnem.2013-0161

13. Petrie T, Greenleaf C. Body image and sports/athletics. Encyclopedia of body image and human appearance. Elsevier; 2012:160-165.

14. Hodler MR, Lucas-Carr C. "The mother of all comebacks" a critical analysis of the fitspirational comeback narrative of dara torres. Communication \& Sport. 2016;4(4):442-459. doi:10.1177\%2F2167479515583480

15. Coyne P, Woodruff SJ. Examining the influence of crossfit participation on body image, self-esteem, and eating behaviours among women. Journal of Physical Education and Sport. 2020;20(3):1314-1325. doi:10.7752/jpes.2020.03183

16. Dawson MC. Crossfit: Fitness cult or reinventive institution? International Review for the Sociology of Sport. 2017;52(3):361-379. doi:10.1177\%2F1012690215591793

17. Heinrich KM, Becker C, Carlisle T, et al. High-intensity functional training improves functional movement and body composition among cancer survivors: A pilot study. European Journal of Cancer Care. 2015;24(6):812-817. doi:10.1111/ecc.12338

18. Herz JC. Learning to breathe fire: The rise of crossfit and the primal future of fitness. Harmony; 2015.

19. Heywood L. 'We're in this together:'neoliberalism and the disruption of the coach/athlete hierarchy in crossfit. Sports Coaching Review. 2016;5(1):116-129. doi:10.1080/21640629.2016.1198581

20. CrossFit. What is crossfit? . CrossFit. 2018. Accessed August 08, 2021. https://www.crossfit.com/what-iscrossfit

21. Myers TA, Crowther JH. Social comparison as a predictor of body dissatisfaction: A meta-analytic review. Journal of Abnormal Psychology. 2009;118(4):683. doi:10.1037/a0016763

22. Pempek TA, Yermolayeva YA, Calvert SL. College students' social networking experiences on facebook. Journal of Applied Developmental Psychology. 2009;30(3):227-238. doi:10.1016/j.appdev.2008.12.010

23. James EP, Gill R. Neoliberalism and the communicative labor of crossfit. Communication \& Sport. 2018;6(6):703-727. doi:10.1177\%2F2167479517737036

24. Washington MS, Economides M. Strong is the new sexy: Women, crossfit, and the postfeminist ideal. Journal of Sport and Social Issues. 2016;40(2):143-161. doi:10.1177\%2F0193723515615181

25. Swami V. Is crossfit associated with more positive body image? A prospective investigation in novice crossfitters. International Journal of Sport Psychology. 2019;50(4):370-381. doi:10.7352/IJSP.2019.50.370

26. Knapp BA. Gender representation in the crossfit journal: A content analysis. Sport in Society. 2015;18(6):688703. doi:10.1080/17430437.2014.982544

27. Engeln R, Loach R, Imundo MN, Zola A. Compared to facebook, instagram use causes more appearance comparison and lower body satisfaction in college women. Body Image. 2020;34:38-45. doi:10.1016/j.bodyim.2020.04.007

28. Prichard I, Kavanagh E, Mulgrew KE, Lim MS, Tiggemann M. The effect of instagram\# fitspiration images on young women's mood, body image, and exercise behaviour. Body Image. 2020;33:1-6. doi:10.1016/j.bodyim.2020.02.002 
29. Saunders JF, Eaton AA. Snaps, selfies, and shares: How three popular social media platforms contribute to the sociocultural model of disordered eating among young women. Cyberpsychology, Behavior, and Social Networking. 2018;21(6):343-354. doi:10.1089/cyber.2017.0713

30. Chase SE. Narrative inquiry: Multiple lenses, approaches, voices. In the sage handbook of qualitative research. Thousand Oaks: Sage Publications Ltd.; 2005.

31. Polkinghorne DE. Language and meaning: Data collection in qualitative research. Journal of Counseling Psychology. 2005;52(2):137. doi:10.1037/0022-0167.52.2.137

32. Wilkinson S. Focus groups in health research: Exploring the meanings of health and illness. Journal of Health Psychology. 1998;3(3):329-348. doi:10.1177\%2F135910539800300304

33. Elo S, Kyngäs H. The qualitative content analysis process. Journal of Advanced Nursing. 2008;62(1):107-115. doi:10.1111/j.1365-2648.2007.04569.x

34. Myers TA, Ridolfi DR, Crowther JH, Ciesla JA. The impact of appearance-focused social comparisons on body image disturbance in the naturalistic environment: The roles of thin-ideal internalization and feminist beliefs. Body Image. 2012;9(3):342-351. doi:10.1016/j.bodyim.2012.03.005

35. Rubin LR, Nemeroff CJ, Russo NF. Exploring feminist women's body consciousness. Psychology of Women Quarterly. 2004;28(1):27-37. doi:10.1111/j.1471-6402.2004.00120.x

36. Podmore M, Ogle JP. The lived experience of crossfit as a context for the development of women's body image and appearance management practices. Fashion and Textiles. 2018;5(1):1-23. doi:10.1186/s40691-017-0116-y

37. Heywood L. 'Strange borrowing': Affective neuroscience, neoliberalism and the 'cruelly optimistic'gendered bodies of crossfit. Twenty-first century feminism. Springer; 2015:17-40.

38. Holland G, Tiggemann M. "Strong beats skinny every time": Disordered eating and compulsive exercise in women who post fitspiration on instagram. International Journal of Eating Disorders. 2017;50(1):76-79. doi:10.1002/eat.22559

39. Tiggemann M, Zaccardo M. "Exercise to be fit, not skinny": The effect of fitspiration imagery on women's body image. Body Image. 2015;15:61-67. doi:10.1016/j.bodyim.2015.06.003

40. Halliwell E. The impact of thin idealized media images on body satisfaction: Does body appreciation protect women from negative effects? Body Image. 2013;10(4):509-514.

41. Alleva JM, Martijn C, Van Breukelen GJ, Jansen A, Karos K. Expand your horizon: A programme that improves body image and reduces self-objectification by training women to focus on body functionality. Body Image. 2015;15:81-89. doi:10.1016/j.bodyim.2015.07.001

42. Avalos LC, Tylka TL. Exploring a model of intuitive eating with college women. Journal of Counseling Psychology. 2006;53(4):486. doi:10.1037/0022-0167.53.4.486

43. Homan KJ, Tylka TL. Appearance-based exercise motivation moderates the relationship between exercise frequency and positive body image. Body Image. 2014;11(2):101-108. doi:10.1016/j.bodyim.2014.01.003

44. Vartanian LR, Wharton CM, Green EB. Appearance vs. Health motives for exercise and for weight loss. Psychology of Sport and Exercise. 2012;13(3):251-256. doi:10.1016/j.psychsport.2011.12.005 